\title{
Implementation of Frequency Drift for Identification of Solar Radio Burst Type II
}

\author{
Nur Zulaikha Mohd Afandi", Zamri Zainal Abidin", Roslan Umar", Nor Hazmin Sabri", Zainol Abidin \\ Ibrahim $^{*}$ Christian Monstein ${ }^{\#}$ \\ ${ }^{\#}$ East Coast Environmental Research Institute, Universiti Sultan Zainal Abidin, Kuala Nerus, Terengganu, 21300, Malaysia \\ E-mail:zulaikhafendy@yahoo.com.my; roslan@unisza.edu.my \\ *Department of Physics, University of Malaya, Kuala Lumpur50603, Malaysia \\ E-mail: zzaa@um.edu.my;drzai@um.edu.my
}

${ }^{*}$ School of Fundamental Science, Universiti Malaysia Terengganu, Terengganu, 21030, Malaysia

E-mail: norhazmin@umt.edu.my

"Institute for Astronomy, ETH Zurich, HIT J13.2, Wolfgang-Pauli-Strasse 27, Zurich, CH-8093, Switzerland

E-mail: monstein@astro.phys.ethz.ch

\begin{abstract}
Sun is constantly produced mass and radiation during its natural activities, which will interact with ionosphere and affect the earth weather. In radio astronomer community, CALLISTO is used to capture the radio signal comes from solar activities such as solar burst. Solar flares and Coronal Mass Ejections (CMEs) were closely associated with the production of solar radio burst Type II and III. However, the determination of solar burst existence is done manually using spectrograph which appears for every 15 minutes. In order to assist the solar radio researcher to speed up the process of solar burst identification and detection, this work presents a new algorithm to auto classify solar radio burst Type II and III. The value of frequency drift was used as the main idea in this auto classify algorithm because it can easily implemented using MATLAB. There are three main steps involved named as pre-processing, identification and classification. Auto calculation of frequency drift burst on spectra was obtained from two parts which are frequency axis (df) and time axis (dt). The results of the frequency drift implementation in classification algorithm show that the algorithm developed gave almost similar determination as in manual detection. However, there are always have rooms for improvement for better detection system in future which may include specific characterization of bursts and improved noise elimination.
\end{abstract}

Keywords — radioastronomy, solar radio burst, CALLISTO, auto classification, frequency drift.

\section{INTRODUCTION}

The Sun emits electromagnetic radiation and charged particles [1] towards and away from surface of the Sun during eruption due to the nuclear fusion between hydrogen and helium. Solar electromagnetic radiation is generating infrared (IR) to ultraviolet energy sources in the electromagnetic spectrum. However, emission of radio up to an X-rays wavelength also produced by event of solar flares [2]. Besides the solar flare activity, Coronal Mass Ejections (CMEs) also the example of solar activity which is contribute to produce Solar Energetic Particles [3]. This energetic particle accelerates through the interplanetary medium during solar wind and able to disturb the atmosphere of other planets in the solar system. According to [4], solar flare able to eject electron until $1 \times 10^{36}$ electrons per second, it was given a great potential risk to satellite communications, spacecraft and ground-base technology. So that, in [5] stated that solar flare is thought to be the factor for radio burst to be occurred several times in maximum solar cycle. Normally, space weather forecast is focused on monitoring solar flare in the radio region in order to classify their mechanism and properties of flare productions [6]. In general, solar radio burst is a non-thermal emission which is come from radiation occurred between energetic charged particles collide with magnetic field, electric field of other charged particles and plasma radiation. So that, the radio burst come in a variety of frequency and time [7]. Not only that, monitoring solar radio burst also important because it can give the properties of the Sun including amount of radiation [8]. Generally, solar radio burst can be classified 
into five types that consist of; noise-storm burst (Type I), slow-drift burst (Type II), fast drift burst (Type III), broadband continuum emission (Type IV) and continuum emission at meter wavelength (Type V) [9]. Each type of burst was classified by frequency range and duration has been summarized in Table I.

TABLE I

CLASSIFICATION BURST AT METRIC WAVELENGTH

\begin{tabular}{|c|c|c|c|}
\hline $\begin{array}{c}\text { Typ } \\
\text { e } \\
\text { Burs } \\
\text { t }\end{array}$ & $\begin{array}{c}\text { Frequency } \\
\text { Range }\end{array}$ & Duration Time & $\begin{array}{c}\text { Frequency } \\
\text { Drift }(\mathrm{MHz} / \mathrm{sec})\end{array}$ \\
\hline I & $\begin{array}{c}\text { Mostly: < } \\
200 \mathrm{MHz} \\
\text { Rare: > } \\
250 \mathrm{MHz}\end{array}$ & $\begin{array}{c}\text { Single burst: } 10^{1} \\
\text { to } 10 \text { seconds } \\
\text { Storm: hours to } \\
\text { days }\end{array}$ & Mostly: > 100 \\
\hline II & $\begin{array}{c}\text { Mostly: < } \\
150 \mathrm{MHz} \\
\text { Rare: }>150 \mathrm{M} \\
\mathrm{Hz}\end{array}$ & $\begin{array}{c}\text { 5-30 minutes } \\
\text { Ave: } 10 \text { minutes }\end{array}$ & Mostly: $<0.1$ \\
\hline III & $10 \mathrm{kHz}-1 \mathrm{GHz}$ & $\begin{array}{l}\text { Single burst: } 10 \\
\text { second group: } 1- \\
5 \text { minutes } \\
\text { Storm: minutes to } \\
\text { hours } \\
\end{array}$ & $\begin{array}{c}\text { Single burst: }> \\
0.1 \\
\text { Group and } \\
\text { Storm: }>0.1\end{array}$ \\
\hline $\begin{array}{l}\text { IV } \\
\text { a. } \\
\text { Stati } \\
\text { onar }\end{array}$ & $\begin{array}{c}20 \mathrm{MHz}- \\
2 \mathrm{GHz}\end{array}$ & & Mostly: > 10 \\
\hline $\begin{array}{l}\text { y } \\
\text { b. } \\
\text { Mov } \\
\text { ing }\end{array}$ & $\begin{array}{l}20 \mathrm{MHz}- \\
400 \mathrm{MHz}\end{array}$ & $\begin{array}{c}\text { Hours to days } \\
\begin{array}{c}30 \text { minutes- } \\
\text { hours }\end{array}\end{array}$ & \\
\hline $\begin{array}{l}\text { c. } \\
\text { Flare } \\
\text { conti } \\
\text { nua }\end{array}$ & $\begin{array}{l}25 \mathrm{MHz}- \\
200 \mathrm{MHz}\end{array}$ & 3-45 minutes & \\
\hline V & $\begin{array}{c}<150 \mathrm{MHz} \\
\text { or } 10-200 \\
\mathrm{MHz}\end{array}$ & $\begin{array}{l}1-3 \text { minutes } \\
<1 \text { minute }\end{array}$ & $\begin{array}{l}\text { Mostly: same as } \\
\text { burst Type II }\end{array}$ \\
\hline
\end{tabular}

(Credit to Solar Radio Burst Classifications by Australian Space Weather and Callisto Burst Catalogue Spectra)

In this study, Type II and Type III burst have been investigated using their frequency drift on spectrum. Solar radio burst Type II has slow frequency drift, was found in 1947. Many assumptions about the origin of this type of solar burst, but the latest found in [10] which stated that it occurs from magnetohydrodynamic (MHD) shock waves that produce very fast moving electrons. It has two shapes of coronal consecutive; fundamental and second harmonics. Report of [11] stated that burst Type III occurs from the kinetic electron propagates along the magnetic field of the Sun, also linked from the CMEs [12]. It is a fast drift because most of these burst appear in the spectrum with a short period of time. There are three forms that are classified as Type III burst which are single, group or storm form with different duration time. Some of this fast drift eruption would have existed pair with radio burst Type V [13]. Furthermore, the features of this burst were quite similar with Type V burst (Credit to Catalogue Solar Radio Burst Classifications by Australian Space Weather Service). Both type solar radio burst type II and III are highly correlated with fast-electron and emission being at plasma frequency and/or it second harmonic [14]. Due to the solar emission disturbance, a lot research found effects to weather of Earth such as Extreme Ultraviolet Lithography (EUV) radiation at polar region, changes in geophysical and ground-base technology. So that, monitoring of solar activity was very important for solar research and space weather [15]. Since emission from the Sun is able to be detected at radio frequency range, number of radio receivers and magnetometers are introduced since 1800's to monitor 24 hours solar flare activity. The radio receiver must able to detect space signal within specific range of frequency and wavelength [16].

Basically, emission of solar radio received by radio spectrometer recorded in dynamic spectrum with different of relative logarithmic intensity. The existence of radio solar can clearly see with hot intensity which is representing the energy of the particle charges brought by the shock wave. As known that each type of solar radio burst has owns characteristics to represent the original emission source. Due to the importance of radio burst associated with Earth disturbance, the investigation of solar burst become popular within astrophysicist. One of them is solar observation using CALLISTO (Compact Astronomical Low-Cost Low Frequency Instrument for Spectroscopy in Transportable Observatories) spectra founded and developed by Christian Monstein [17]. This system needs the observer to view the spectrum manually for each station for every 15 minutes, 24 hours a day. This practice is prone to human error and time consuming. In this modern technology, all results can be analysed automatically in real time with high accuracy. Thus, a lot of work have been presented the automatic classification using image processing for example the system developed by [18]-[20] using Interactive Data Language (IDL). In this study, the automated classification system was developed using MATLAB programming and offers different classification method by using frequency drift calculation.

\section{METHODOLOGY}

In this study, about 200 spectrum data collected from various CALLISTO stations for analysis. This instrument has time resolution about $0.25 \mathrm{sec}$ at 200 channels per spectrum ( 800 pixels per second). It can generate data by 400 frequencies per sweep which is saved automatically into computer. All data are available free to download and it was updated in real-time. The flowchart of the algorithm developed for burst classification is shown in Fig. 1.

This 24-hour-observation of radio spectrometer along the year covered low frequency range from $45 \mathrm{MHz}$ to $870 \mathrm{MHz}$. The output spectrum dynamic image is displayed in Flexible Image Transport System (FITS) format with twodimensional matrix array containing the value of intensity. Due to many factors, the logarithm of the relative brightness is rated from 0 to 255 . The size of each spectrum is a $200 \mathrm{x}$ 3600 matrix, with rows and column represent frequency and time respectively. MATLAB software was chosen to carry out the analysis of burst classification because it is a wellknown programming language and has been widely used by researchers and engineers for analysis of wave signal. The language is robust and contain image processing tool. Four spectral analyses selected for this study are listed in Table II. 
The selected spectrums analysed are those which have been classified manually as burst Type II and III at different date, time and station through e-Callisto network.

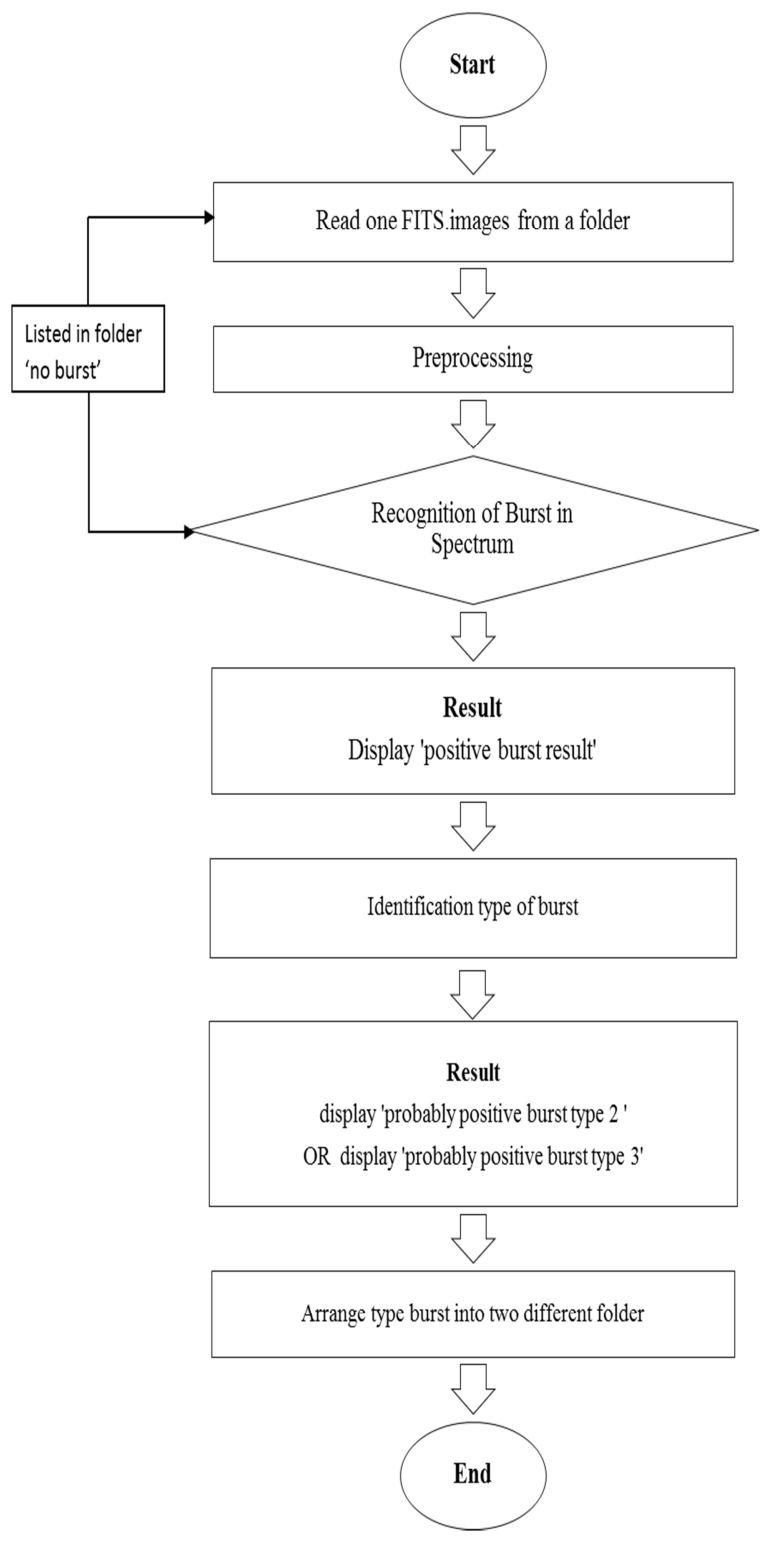

Fig. 1 Flow chart of the developed algorithm

TABLE III

LISTED SELECTED SPECTROGRAPH

\begin{tabular}{|c|c|c|c|c|}
\hline $\begin{array}{c}\text { Event } \\
\text { No. }\end{array}$ & Date & $\begin{array}{c}\text { Start Time } \\
(\mathbf{U T})\end{array}$ & $\begin{array}{c}\text { Range of } \\
\text { Frequenc } \\
\mathbf{y}(\mathbf{M H z})\end{array}$ & $\begin{array}{c}\text { CALLISTO } \\
\text { Station }\end{array}$ \\
\hline 1. & $\begin{array}{c}\text { January } \\
8,2014\end{array}$ & $03: 44: 38$ & $150-850$ & $\begin{array}{c}\text { Poste de Flacq, } \\
\text { Mauritius }\end{array}$ \\
\hline 2. & $\begin{array}{c}\text { April } \\
13,2014\end{array}$ & $02: 59: 38$ & $50-850$ & $\begin{array}{c}\text { Almaty, } \\
\text { Kazakhstan }\end{array}$ \\
\hline 3. & $\begin{array}{c}\text { June } \\
12,2014\end{array}$ & $10: 14: 38$ & $100-200$ & $\begin{array}{c}\text { Birr Castle, } \\
\text { Ireland }\end{array}$ \\
\hline 4. & $\begin{array}{c}\text { August } \\
22,2014\end{array}$ & $10: 44: 37$ & $10-105$ & $\begin{array}{c}\text { Birr Castle, } \\
\text { Ireland }\end{array}$ \\
\hline
\end{tabular}

Data was downloaded from e-callisto.org network
Two dimensions array were noted as $f_{n}$ for frequency and $t_{m}$ for time correspond to the rows and columns of the matrix. The original dynamic spectrum collected from eCALLISTO for all four days selected is shown in Fig. 2.

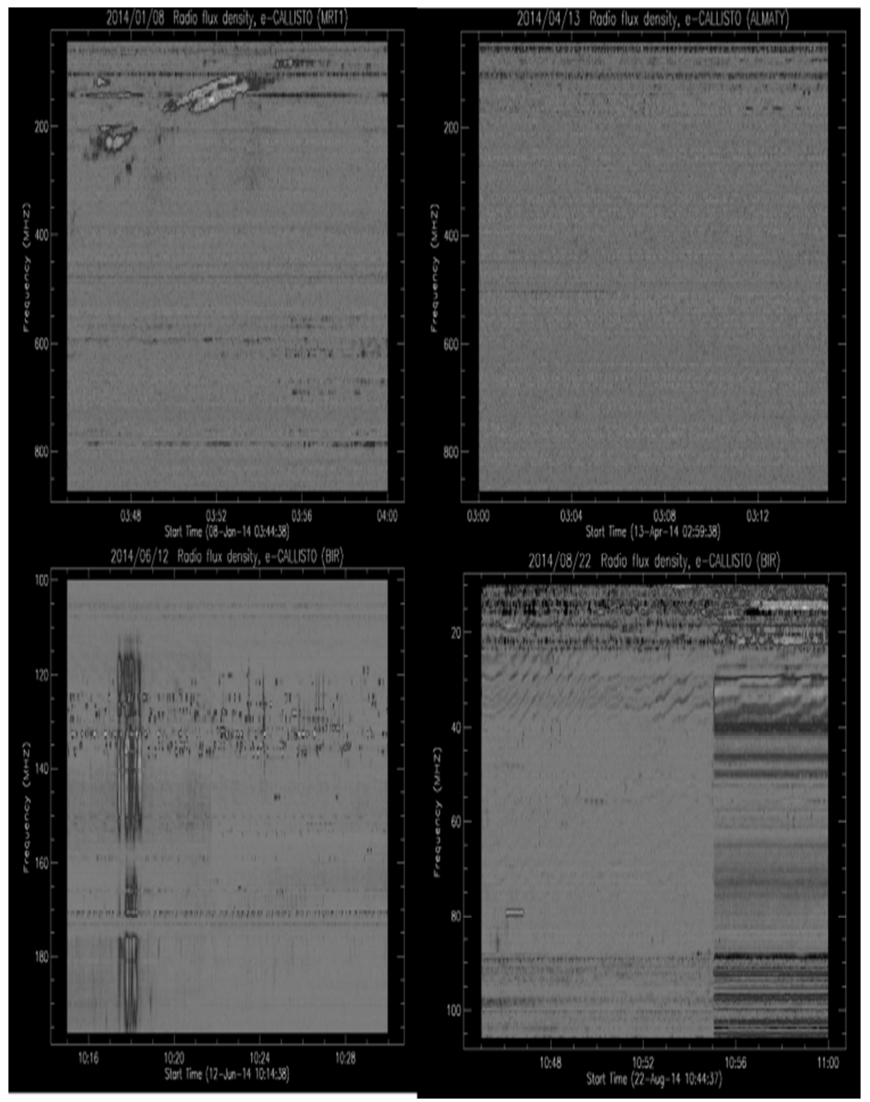

Fig. 2 The dynamic spectrum listed from Table II

In data elements, there is a mixture between noise and real burst data in term of intensity/brightness. Usually, noise is the formation of horizontal lines with very high brightness levels on the spectrum that comes from electromagnetic interference based communication. Therefore, background cancellation algorithm has been applied after the system reads each image spectrum. Background noise is created due to the rejection process between real data and background image. This involves statistical parameters such as maximum, mean, standard deviation and covariance of the frequency axis. Then, clean data matrix without the noise was obtained after the filtration. This process was called as pre-processing stage.

The next algorithm function is the most important part in this study because this stage are focus more on the appearance of 'events' on FITS image. The emergence of the 'event' refers to the recognition of the burst on the spectrum. Recognition of this burst is not easy because the spectrum is plotted in time-frequency array with data in logarithmic form of whole numbers. However, image processing techniques have been used even a small error still exists, called image enhancement algorithms. Before the enhanced image brightness, there are two steps that need to be done; plotting the maximum value of the data points as Fig. 3 and determines the threshold of the intensity. In the first step, the intensity value of the data for each row which 
represent the same frequency were analysed to get the maximum value.

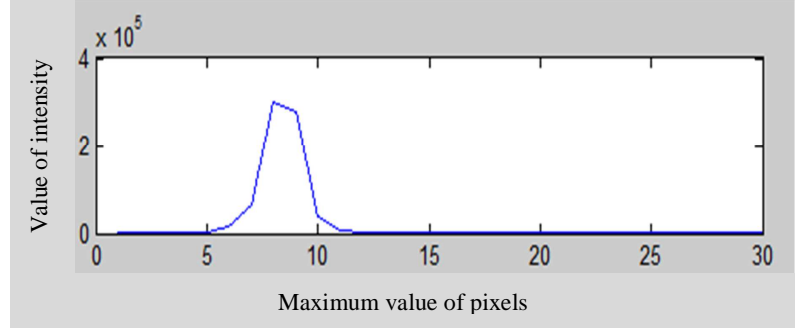

Fig. 3 The maximum value of data pixels

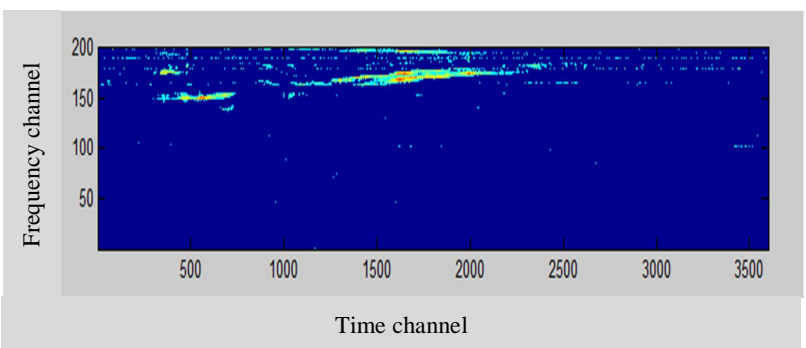

Fig. 4 The burst have been clearly exist after comparison the intensity with threshold value

Next, the second step is where the threshold of intensity for the same row is determined based on the burst characteristic. This simplifies the verification of the presence of the eruptions with eruptive events in the absence of spectrum as Fig. 3. However, there are some small noise appear on the spectrum, so that the median filtering is applied. The result from this step will produce the spectrum recognition whether as "no burst" which classified as no burst detected or "burst" which means the spectrum may contain burst. Only the spectrum detected as "burst" may proceed to the next stage, named classification stage.

Classification stage is the determination of the solar radio burst type. In this stage the spectrum were classified whether the burst is Type II or III. The difference between the two type of solar burst can be manually seen from the event duration and the frequency of the burst. The frequency drift is determined by calculating the changes in the frequency axis and time axis. Then, the value was compared with the threshold to determine the burst type.

\section{RESULTS AND DISCUSSION}

After the original spectrum was transferred into MATLAB, the color intensity was slightly different from the image on the network as Fig. 5. This is because the intensity of color is depending on the capability of the software to translate in image.

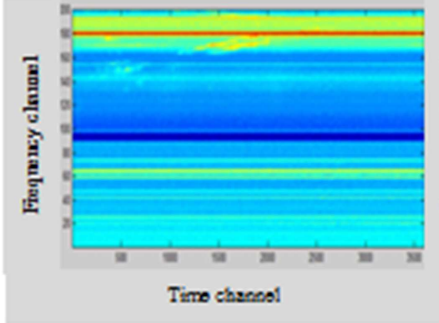

(a)

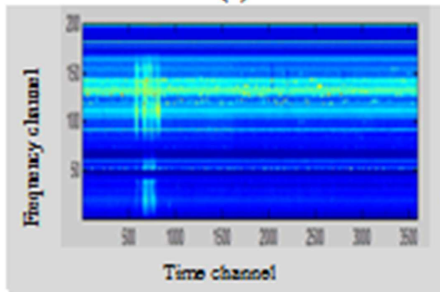

(c)

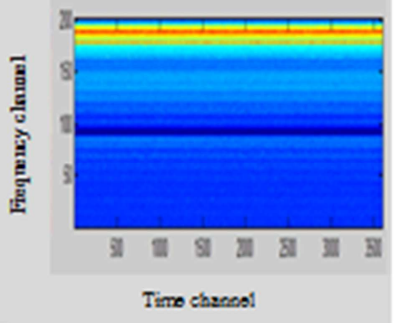

(b)

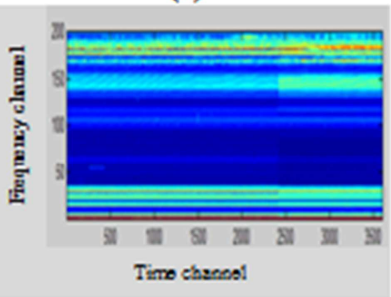

(d)
Fig. 5 The dynamic original spectrum as view in MATLAB for a) 8th January 2014, b) 13th April 2014, c) 12th June 2014,d) 22nd August 2014

As explained previously, in pre-processing step, background cancellation process took part as to minimize the noise. The spectrum image after pre-processing step is shown in Fig. 6. Generally, high intensity on the spectrum is corresponds to the burst event. Intensity enhancement was dome to detect the existence of the burst. The dynamic spectrum after intensity enhancement is shown in Fig. 7.

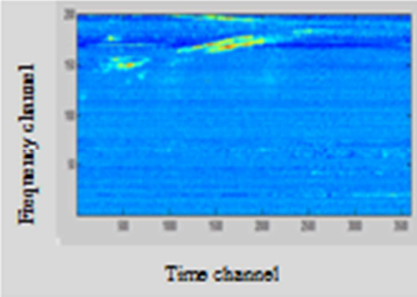

(a)

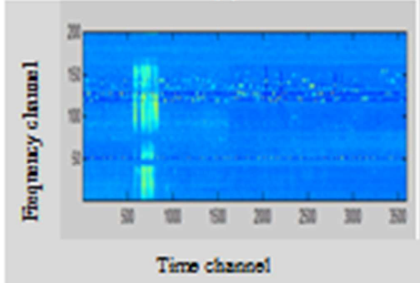

(c)

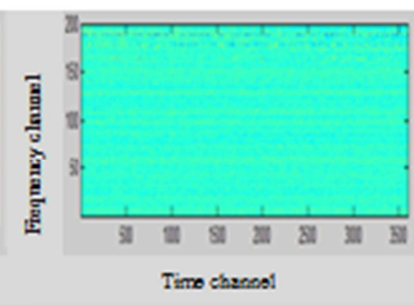

(b)

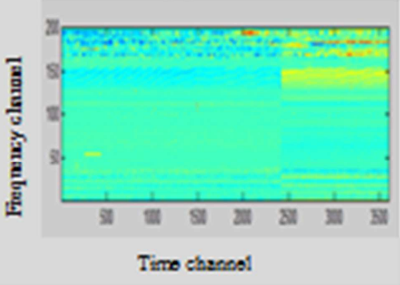

(d)
Fig. 6 The dynamic spectrum after background cancellation a) 8th January 2014, b) 13th April 2014, c) 12th June 2014, d) 22nd August 2014 


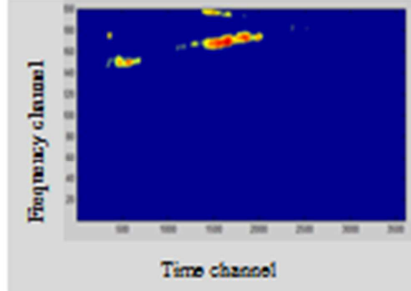

(a)

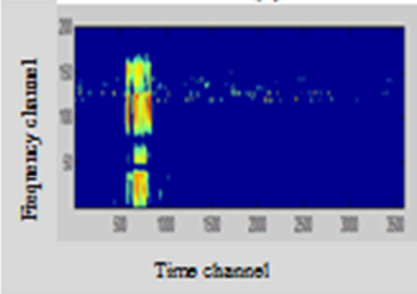

(c)

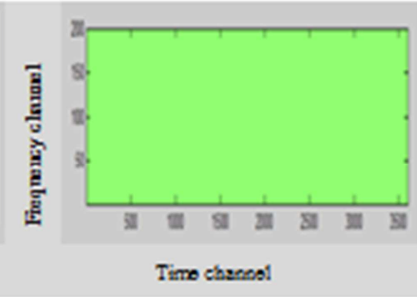

(b)

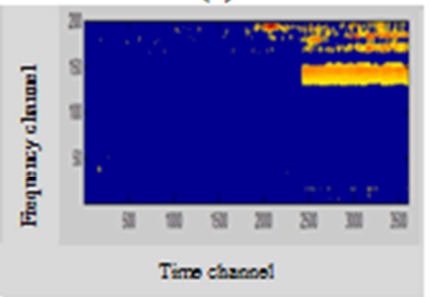

(d)
Fig. 7 The dynamic spectrum after intensity enhancement a) 8thJanuary 2014, b) 13th April 2014, c) 12th June 2014, d) 22nd August 2014

Burst duration, frequency and intensity shape are three characteristics to distinguish between this two burst. For further classification analysis, one can use the frequency drift rate which can be determined using programming language. Two main aspects in the frequency drift were frequency and time. As known, drift of burst is fast move from high frequency into low frequency within certain duration. Actually, it is related to the disturbance due to activity of plasma emission in coronal gas. For duration of burst is approximately based on the power law as follows [18]

$$
f(t)=a(t-b)^{-\alpha}
$$

where $a$ and $b$ are constants and $\alpha$ is the power law index, which is approximately near to 1 . In the other hand, the duration of burst is depending on the frequency range of burst. With applying these elements into classification stage, the burst have been classified and summarized in Table III.

TABLE III

RESULT OF BURST CLASSIFICATION FROM DEVELOPED ALGORITHM

\begin{tabular}{|c|c|c|c|}
\hline $\begin{array}{c}\text { Event } \\
\text { N. }\end{array}$ & $\begin{array}{c}\text { Positive burst } \\
\text { Type II }\end{array}$ & $\begin{array}{c}\text { Positive burst } \\
\text { Type III }\end{array}$ & $\begin{array}{c}\text { Manual } \\
\text { Classification } \\
\text { Result }\end{array}$ \\
\hline 1. & 1 & 0 & Type II \\
\hline 2. & 0 & 0 & No burst \\
\hline 3. & 0 & 1 & Type III \\
\hline 4. & 1 & 0 & Noise \\
\hline
\end{tabular}

Result '1' indicates the positive result, while '0' indicate the negative in burst result. It is clearly seen from Table III, spectrum event 3 which is at Kazakhstan on 13th April 2014 show negative result for both burst. This is because this spectrum does not have appearance of any 'burst'. The first and third spectrum event are correctly recognized their burst type. This was because $\mathrm{x}$-ray flux data from Geostationary Operational Environmental Satellite (GOES) spacecraft on Fig. 8 show type M-flare occurred during on that time and date.

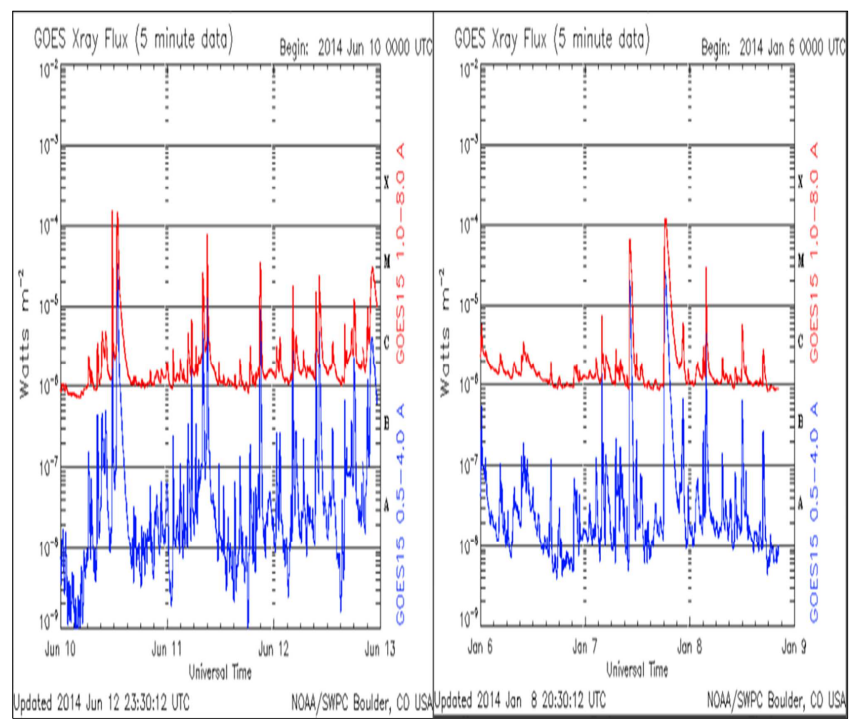

Fig. 8 GOES X-ray flux data on 8th January 2014 and 12th June 2014 (Credited from to NOAA/SWPC)

Additional evidence of solar burst detection had been recorded by other CALLISTO stations on the same time and date. It can be clearly seen by several stations as following Fig. 9 and Fig. 10.

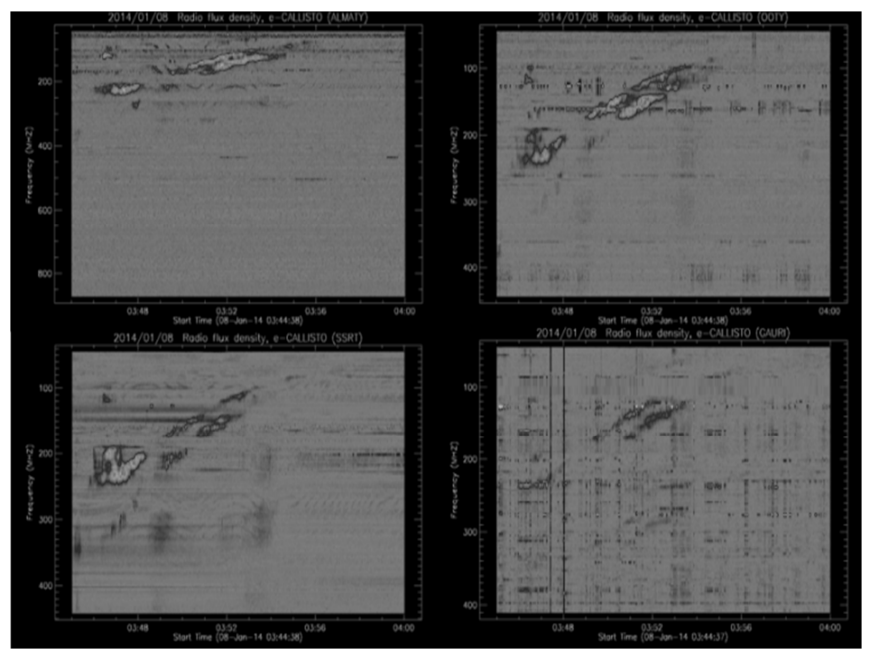

Fig. 9 Spectrum data on 8th January 2014 from Almaty, Kazakstan; Badary,Russia; Ooty, India and Gauribidanur, India

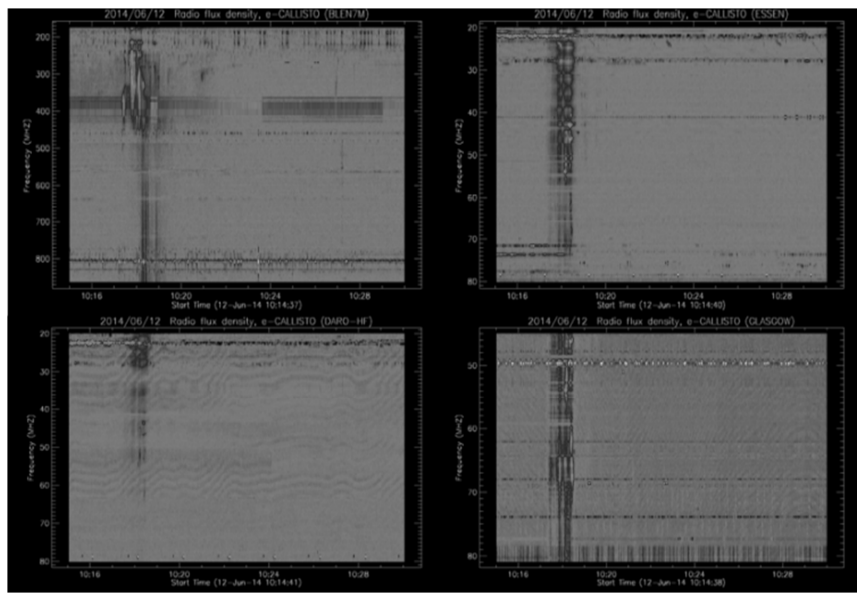

Fig. 10 Spectrum data on 12th June 2014 from Bleien, Switzerland; DRAO, Germany; Essen, Germany and Glasgow, UK 
However, the fourth spectrum is mis assigned as burst Type II. It is actually classified as noise manually from the display. The algorithm misrecognized the spectrum may be because it appeared in constant intensity and coincidentally the noise value was similar to the burst intensity. However, this algorithm manages to produce a new, simple algorithm and quick result to apply in the solar observation research, specifically in determining the existence of burst from eCALLISTO data. Future enhancement on the algorithm needs to be done to avoid misrecognition of the solar activity type. The criteria for determining the characteristics of the classes of solar radio burst need to be studied deeply and more steps need to be inserted in the algorithm.

\section{CONCLUSIONS}

This project presented the new method to identify the burst type II and III automatically from the dynamic spectrum displayed by Callisto spectrometer. These algorithms may benefit solar activity research and reduce time consuming in reading the appearance of burst event from CALLISTO images which is presently done manually. Further research on solar activities occurrence such as burst, solar flare and coronal mass ejection will be assisted by this automated system and the solar activity pattern is possible to predict. This algorithm needs to be enhanced in order to provide an efficient recognition and classification system for solar burst. It not quite efficient method because the algorithm classifiers to class this eruption uses only one criterion for the determination on the characteristics of the classes of solar radio burst.

\section{ACKNOWLEDGMENT}

This study was supported by grant RACE-UM (CR0082015), FRGS (FRGS/1/2015/SG02/UNISZA/02/1) and UMT (UMT-68006/INSENTIF/60). The author is grateful to CALLISTO of ETH Zurich, Switzerland. The author also would like to thank the Malaysia Ministry of Education's FRGS grant (FP034-2013B) for their funding. Special thanks to the IPS Australia and NOAA for classification of burst. Authors would also like to acknowledge Universiti Malaya, Universiti Sultan Zainal Abidin and Universiti Malaysia Terengganu for financial and laboratory access.

\section{REFERENCES}

[1] M. Durante and F. Cucinotta, "Physical basis of radiation protection in space travel," Reviews of Modern Physic, vol. 83, pp. 1245-1281, Nov. 2011.

[2] Z. S. Hamidi, N. N. M. Shariff and C. Monstein, "Characterization of selected solar radio bursts based on solar activity detected by eCALLISTO (Malaysia)," International Letters of Chemistry Physics and Astronomy, vol. 13, pp. 144-154, Jul. 2014.
[3] X. Wang and Y. Yan, "Analysis of the CME-driven shock from the SEP event that occurred on 2006 December 14," Research in Astronomy and Astrophysics, vol. 12, pp. 1535-1548, Nov. 2012.

[4] A. G. Emslie, R. B. Dennis, A. Y. Shih, P. C. Chamberlin, R. A. Mewaldt, C. S. Moore, G. H. Share, A. Vourlidas and B. T. Welsch, "Global energetics of thirty-eight large solar eruptive events," The Astrophysical Journal, vol. 759, pp. 71-117, Oct. 2012.

[5] Z. S. Hamidi, N. N. M. Shariff and C. Monstein, "Occurrences rate of type II and III solar radio bursts at low frequency radio region 45870 MHz," International Letters of Chemistry Physics and Astronomy, vol. 37, pp.103-112, Sep. 2013.

[6] Z. Z. Abidin, N. M. Anim, Z. S. Hamidi, C. Monstein, Z. A. Ibrahim, and R. Umar, N. N. M. Shariff, N. Ramli, N. A. I. Aziz and I. Sukma, "Radio frequency interference in solar monitoring using CALLISTO," New Astronomy Reviews, vol. 67, pp. 18-33, Aug. 2015.

[7] H. A. S. Reid and H. Ratcliffe, "A review of solar type III radio bursts," Research in Astronomy and Astrophysics, vol. 14, pp. 773803, Jul. 2014.

[8] N. Gopalswamy, A. Lara, R. P. Lepping, M. L. Kaiser, D. Berdichevsky and O. C. St Cyr, "Interplanetary acceleration of coronal mass ejections," Geophysical Research Letters, vol. 27, pp. 145-148, Jan. 2000.

[9] M. R. Kundu, Solar Radio Astronomy, New York, USA: Inderscience Publication, 1965.

[10] P. Zucca, E. P. Carley, J. McCauley, P.T. Gallagher, C. Monstein, and R. T. J. McAteer, "Observations of low frequency solar radio bursts from the Rosse solar-terrestrial observatory," Solar Physics, vol. 280, pp. 591-602, Oct. 2012.

[11] N. Gopalswamy, "Coronal mass ejections and solar radio emissions," in Proc. PRE VII'11, 2011, p. 325-342.

[12] M. Wang, G. Gao, R. Xie and C. Tan, "Possible radio precursors/signatures of the CMEs onset: Radio type III bursts and fine structures in the centimeter-metric wavelength region," Research in Astronomy and Astrophysics, vol. 11, pp. 607-616, Dec. 2011.

[13] N. Ramli, Z. S. Hamidi, Z. Z. Abidin and S. N. Shahar, "The relation between solar radio burst types II, III and IV due to solar activities," in Proc. IconSpace'15, 2015, p. 123-127.

[14] D. G. Wentzel, "Solar radio emission very near the plasma frequency," The Astrophysical Journal, vol. 270, pp. 250-255, Jul. 1983.

[15] N. H. Sabri, A. W. Azlan, R. Umar, S. S. Sulan, Z. A. Ibrahim and W. Z. A. W. Mokhtar, "The effect of solar radiation on radio signal for radio astronomy purposes," Malaysian Journal of Analytical Sciences, vol. 19, pp. 1374-1381, Jul. 2015.

[16] R. Umar, N. H. Sabri, Z. Z. Abidin, Z. A. Ibrahim, A. Azid, H. Juahir, M. E. Toriman and M. K. A. Kamarudin, "Preliminary study of radio astronomical lines effect of rain below $2.9 \mathrm{GHz}$," Jurnal Teknologi, vol. 75, pp. 7-11, Jun. 2015.

[17] A. Benz, C. Monstein and H. Meyer, "CALLISTO-A new concept for solar radio spectrometers," Solar Physics, vol. 226, pp. 143-151, Jan. 2005.

[18] V. V. Lobzin, I. H. Cairns, P. A. Robinson, G. Steward and G. Patterson, "Automatic recognition of type III solar radio bursts: Automated radio burst identification system method and first observations," Space Weather, vol. 7, pp. 1-12, Apr. 2009.

[19] V. V. Lobzin, I. H. Cairns, P. A. Robinson, G. Steward and P. Patterson, "Automatic recognition of coronal type II radio bursts: The automated radio burst identification system method and first observations," The Astrophysical Journal Letters, vol. 710, pp. 58-62, Jan. 2010.

[20] L. Ma, Z. Chen, L. Xu and Y. Yan, "Multimodal deep learning for solar radio burst classification," Pattern Recognition, vol. 61, pp. 573-582, Jan. 2017. 